\title{
La reproducción del discurso de ARENA en la prensa escrita y en la publicidad en el período electoral presidencial de 2009
}

NATALY GUZMÁN

Departamento de Letras, Comunicaciones y Periodismo

UCA, San Salvador

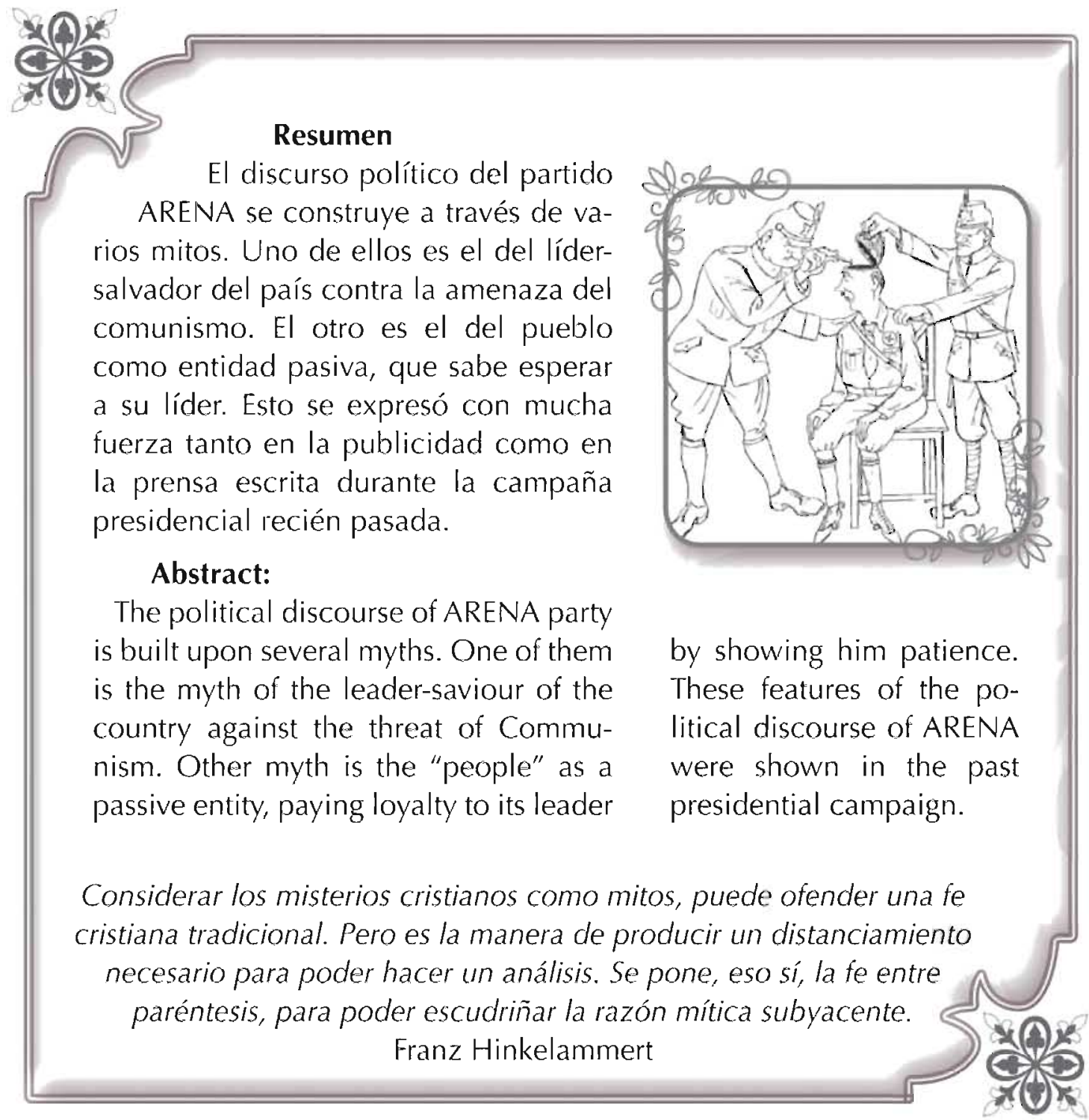


En el año 2002, el Presidente de los Estados Unidos George W. Bush utilizó un eslogan que a partir de entonces redefiniría el rostro del enemigo de turno para "América" en el nuevo siglo: el "Eje del Mal" o The Axis of Evil. El conjunto de mitos que ha manejado el discurso político norteamericano a lo largo de la historia le ha permitido configurar su mito central: los Estados Unidos amenazados por un enemigo que los acecha de forma permanente.

El uso de este tipo de referentes que configuran su sistema mítico para Ilamar la atención de los ciudadanos y sostener, con cierta legitimidad pública, las decisiones políticas del país norteamericano no es nada nuevo. Durante la Segunda Guerra Mundial se utilizó la expresión "Estados canallas" (Rogue States), y el mismo Reagan, durante su administración presidencial en la década de los ochenta, denominó a la Unión Soviética "El Imperio del mal" (The Evil Empire).

Al mito del enemigo en acecho permanente se le suma el mito de la defensa de la libertad. Ambos son siempre representados como lo que define los actos vandálicos de grupo de personas de mente enferma que quieren apoderarse del mundo para imponer sus creencias y acabar con la fe de las diversas religiones y con las libertades civiles. Esto no sólo se ha visto en guerras que ahora se transmiten a través de CNN y de muchos otros canales. El cine ha contado cientos de veces cómo los regímenes totalitarios tienen como objetivo matar principalmente a los judíos y a los cristianos. Los cómics de súper héroes relatan incansablemente cómo los enemigos de "América" pretenden matar a todos los estadounidenses sin distinguir entre militares y civiles, incluso sin distinguir entre mujeres y niños, al mismo tiempo que detonan edificios emblemáticos y siembran el terror en las calles.

Construcciones míticas como estas, sus campos semióticos y sus respectivas representaciones, discursivas como mediáticas, han sabiclo inspirar a la de lo contrario insípida imaginación de la derecha salvadoreña a la hora de construir sus propias versiones de la historia. Por ello, el presente estudio tratará de identificar cómo la prensa escrita y la publicidad reproducen a través de sus enfoques y de sus agendas temáticas elementos narrativo-míticos del discurso de Alianza Republicana Nacionalista (ARENA) en período de elecciones.

Los objetivos son poder observar la coincidencia temática entre algunos elementos de la narrativa mítica y la política, y analizar cómo a pesar de que el discurso político electoral de ARENA se apoya en datos estadísticos, en proyectos concretos y en aspectos cruciales de la vida cotidiana -elementos desde los que se observa la lectura de $\mathrm{El}$ Salvador como nación en progreso-, todas esas representaciones son parte de un conjunto de ele- 
mentos que configura la narrativa mítica del partido en cuestión.

Para la realización de este estudio se ha tomado en cuenta el contenido de las páginas informativas de La Prensa Gráfica (LPG) y de El Diario de Hoy (EDH), específicamente de la sección de Poli- tica, del período comprendido entre el 6 y el 14 de marzo de 2009. También se han tomado en cuenta algunos productos de la propaganda presidencial, como anuncios televisivos, hojas volantes, publicaciones especiales y rótulos o vallas publicitarias.

\section{El discurso mítico en la cobertura informativa de la campaña presidencial y en la propaganda}

$H$ ay mitos a los que nunca se les confiere tal carácter, pues muchos se resisten a tratarlos como narraciones y construcciones humanas. En este estudio no se discute el mito como fantasía exótica, sino como fundamento de ciertas creencias, estructuras, relatos de la cultura, relatos de legitimación. Se discute, pues, el mito y su relación con la política, pues el mito no es algo del pasado como se asume comúnmente. $Y$ desde esta perspectiva hay que reconocer que definitivamente la misma imposición de la racionalidad como única y verdadera vía para adquirir conocimientos es un mito.

Los elementos clásicos de la narrativa de ARENA no están presentes sólo en discursos o en declaraciones oficiales del partido, también se reproducen en la publicidad en general y en la cobertura informativa de la prensa escrita, entre otros medios. Esta lógica narrativa pretende crear determinados referentes en el imaginario social basándose en relatos ya conocidos, como, por ejemplo, los del Mesías (la figura presidencial que promete luchar por el bienestar de la patria), la peste (los "peligros" de un cambio de "sistema"), la bestia (el enemigo de la libertad nacional), el horizonte utópico (el progreso que sólo los constantes pueden vislumbrar con esperanza), y el pueblo (que recibirá una recompensa a través de su trabajo y de su fe, con limitaciones que no deben cuestionarse porque son parte de un sacrificio).

Durante la recién pasada campaña presidencial, así como ha sucedido en otros períodos electorales, los principales medios de la prensa escrita centraron su atención en la cobertura de temáticas que versan sobre la desconfianza que supuestamente genera el FMLN y sobre los peligros que supondría su triunfo político. La mayoría de notas informativas referentes al candidato 
presidencial Mauricio Funes cuestionaban la seriedad de su imagen y la de su partido, mostraban temáticas referentes a la inconformidad de algunos sectores políticos estadounidenses ante un posible gane de la izquierda, hacían énfasis en los temores del sector empresarial privado y en las declaraciones de quienes sostenían que el FMLN entregaría el país a Hugo Chávez. La mayoría de notas relacionadas con el candidato arenero Rodrigo Ávila se enfocaban en destacar sus excelentes relaciones con los empresarios más importantes del país, en los "verdaderos" cambios que introduciría en el manejo del partido y del Ejecutivo, y en su voluntad por continuar con un proyecto presidencial inclinado a atender al más necesitado y promover el progreso.

La publicidad, por su parte, graficó, o mejor dicho, tornó visibles temores y esperanzas, atribuyéndoles rostros e imágenes emblemáticas. Con ello potenció un mensaje verosímil con características de documento objetivo, logradas por medio de la imagen fotográfica o el recurso audiovisual. Los peligros tomaron formas amenazantes con iconos populares cuya interpretación inmediata era una atribución negativa. Hugo Chávez dejó de ser un sustantivo y adquirió niveles superlativos, con montajes sonoros tan desafiantes y opresivos que lo mostraron como la amenaza fantasma propia de un villano que esperaba resultados desde los confines del mal para atacar e invadir.

Por su parte, Rodrigo Ávila fue midiéndose diversas investiduras en las que buscó reflejar los intereses y necesidades del salvadoreño típico. De campesino a empresario, de ciudadano a político, la relación de imágenes fue alterándose al punto de mutar ineficazmente la presencia del candidato como quien intenta atribuirle humanidad y sentido a los rasgos inertes de un maniquí; el Pigmalión, por ende, en esta ocasión se vio traicionado por su creación cuando esta no alcanzó la vida.

¿Cómo entonces se mezclan y se interconectan estos elementos dentro de la narrativa mítica del partido oficial? ¿Cómo se entretejen estos discursos y sus contenidos con los mitos clásicos ya mencionados y cómo se adecuan los mensajes para que estos se afiancen al imaginario colectivo? A continuación se presentará un análisis en el que se intenta dar respuesta a estas y otras interrogantes planteadas al inicio de este trabajo.

\section{El mito de la defensa de la patria}

a permanente justificación de la L guerra civil que vivió El Salvador por más de diez años puede verse desde la perspectiva del mito de la 
defensa de la patria. ARENA ha vuelto el conflicto bélico y sus secuelas en un problema del que solo fue responsable la guerrilla y en el que el ejército tuvo que intervenir para pelear por esa defensa de la patria.

Esta recurrente mención de la guerra se recicla en los discursos para advertir a la gente de las peligrosas vueltas al pasado. A través del recuerdo personal que cada uno pueda tener del conflicto bélico y por medio de discursos, noticias $y$ propaganda, ARENA advierte a la gente que no debe olvidar la restricción de sus libertades civiles, ni los actos vandálicos en las calles (quemas de llantas, estudiantes encapuchados, persecuciones, tiroteos, etc.). Durante la última etapa de la campaña presidencial de 2009, la prensa escrita hizo alusión a temáticas como "Alegatos de fraude pueden crear violencia" (EDH, portada, marzo 10) o "FMLN y Funes insisten en fraude en la semana final" (LPG, p. 03, marzo 10), aludiendo a que las declaraciones de Funes sobre la posibilidad de un fraude electoral podrían generar inestabilidad $e$ incertidumbres debido a que no presentaba "pruebas" de sus sospechas.

Al mismo tiempo, el discurso del partido ARENA hacía énfasis en la estabilidad que como institución política había promovido durante muchos años, y los medios también lo reflejaron en las entrevistas que incluyeron en su agenda: "Cristiani sostiene que un gobierno del FMLN no sólo no enfrentaría la crisis con firmeza, sino que el país entraría en un ambiente de ingobernabilidad, comenzando al enfrentarse el candidato Mauricio Funes y los líderes del partido comunista, quienes se han tomado el FMLN" (EDH, entrevista con Alfredo Cristiani, p. 2, marzo 10). El presidente Saca afirmó en una entrevista que "tenemos que entender que esto no es un enfrentamiento ARENA-FMLN, este es un enfrentamiento de una gran unidad nacional democrática, encabezada por Ávila y ARENA, frente a un partido que tiene ideas equivocadas, totalmente desfasadas, y que en esta crisis nos llevaría al despeñadero" (LPG, p. 7, marzo 05).

Al predominar este tipo de temas en la agenda periodística, ni ARENA, ni los medios buscan promover un perfil activo, abierto e informado de los votantes; sino más bien un ciudadano amedrentado y desinformado que vaya $y$ vote una $y$ otra vez con una convicción creada por temores.

De acuerdo a Franz Hinkelammert, "los pueblos han perdido el derecho de escoger y de determinar su propia manera de vivir y su futuro. Para determinar eso, necesitan la libertad de opinión y la libertad de elegir programas y candidatos. $\mathrm{Ne}$ cesitan, además, la libertad de elección de la manera de vivir, lo que implica la libertad de introducir en la sociedad una intervención sistemática en los mercados en función de los valores de la convivencia y del bien común" ${ }^{\prime \prime}$. ¿Por cuánto tiem- 
po más se espera que la gente cierre sus expectativas de optar por cualquier otra línea política?

La apuesta fundamental de la campaña de ARENA fue, por su parte, la construcción social del temor ante el partido de izquierda. Frente a la posibilidad de elegir entre uno y otro partido político, ARENA se presentó como el partido tradicional, un gobierno que ha defendido valores como la libertad y la democracia. Se mostró como la única elección posible, como lo estable y lo legítimo. Al mismo tiempo, junto a una serie de imágenes de conflicto y escenas amenazantes de Hugo Chávez, la propaganda negra indicaba: "Si Mauricio Funes gana las elecciones, ¿quién va a gobernar?". La desinformación y la intencionada dirección discursiva son evidentes. La convocatoria al rechazo necesario es la narración que define el mito de enemigo siniestro que se debe combatir; asi, este tipo de espots construyó un ambiente paralelo de sometimiento, control y retro- ceso. La leyenda "yo no entrego El Salvador...", sólo es el cierre de una serie de mensajes publicitarios que plastificaron esa especie de hecatombe predecible que posiblemente ocurriría si un gobierno distinto asumía el poder. El temor al retroceso, o mejor dicho, a perder el sistema de valores adquiridos durante los gobiernos de ARENA se volvió la estrategia manifiesta de propiciar presión y evocar el conflicto armado (referente conocido) como posible futuro para El Salvador.

La Patria y todo lo que ella representa en el imaginario nacionalista de la derecha era lo que estaba en peligro desde este discurso. $\mathrm{El}$ ciudadano se ve interpelado, cuestionado y obligado a mantener el régimen de gobierno actual bajo pena de perder los logros figurados como libertad, seguridad y proyectos de desarrollo social; es el único soldado capaz de blandir su voto para favorecer no a un partido sino a un sistema de vida que le ofrece la utopía alcanzable del futuro de bienestar social, económico y político.

\section{Primero El Salvador: El mito del líder arenero}

- I discurso de la mitología are- nera siempre ha sugerido una visión específica de lo que debe ser el hombre-líder ideal, las aspiraciones válidas que la ciudadanía debe tener con respecto a él, los contactos clave con los que el líder debe contar y la forma adecuada de medir la superación de los obstáculos. Rodrigo Ávila inició su campaña hablando de un país "más justo". Con esto apelaba a la idea de que el país podía llegar a alcanzar niveles más altos de justi- 
cia a pesar de que el camino fuera largo y difícil; además de indicar que el partido estaba consciente de que faltaba mucho por hacer, pero que se podía continuar con el camino hacia el horizonte prometido, ya que en los últimos veinte años ARENA había venido construyendo las bases claves. Su reconocimiento de que faltaban cosas por hacer estaba enfocado en mostrar su propia visión renovada del partido, la visión esperanzadora de un hombre joven que cuenta con el respeto de su institución política y con un amplio margen de decisión para hacer los cambios necesarios.

Aquí la figura simbólica del Mesias juega un papel muy importante pues se ve reflejada en la figura de líder que el partido quiere proyectar. En el Apocalipsis, Juan habla de la segunda venida, que implica la presencia del nuevo Salvador del Mundo, del nuevo líder que va a poder establecer un estado de paz y tranquilidad para el pueblo elegido. En las campañas políticas areneras esto se observa como el indicador de una esperanza posible. De hecho, en cada campaña, el partido ha ido sugiriendo que nos estamos preparando poco a poco para llegar al progreso con cada presidente. Cada uno de ellos ha administrado el país en un determinado momento $y$ ha cosechado logros específicos y cruciales. El discurso sobre el lícler arenero da la impresión de que cada presidente ha ido configurando un punto más a seguir en el escalón del progreso mientras el pueblo (los votantes y sus familias) siguen esperando la venida.

El discurso mítico sobre el líder arenero tradicionalmente comienza con las constantes alusiones del partido a la vida de su fundador, el mayor Roberto d'Aubuisson. El mito de d'Aubuisson describe a un hombre valiente $y$ generoso que luchó incansablemente para liberar al país de las garras del comunismo. Sin embargo, dentro del contexto electoral, el discurso mítico tiende a centrarse más en un perfil similar al de la figura de Alfredo Cristiani, denominado "El presidente de la paz", pues tanto la imagen pública de Armando Calderón Sol como la de Francisco Flores nunca alcanzaron los niveles de popularidad ni de Cristiani ni de su eslogan. Fue hasta que llegó Antonio Saca que el partido presentó un perfil que logró cimentar una estrategia publicitaria sin precedentes. Del mito de la conquista de la paz, el partido pasa al mito de la consolidación del progreso a través del mito del líder arenero en constante superación de sí mismo. Es en ese contexto que se intenta plantear la imagen del siguiente líder que busca la renovación, el cambio y la revitalización del partido.

Tanto en la cobertura informativa de La Prensa Cráfica como en la de El Diario de Hoy predominó la presencia de temáticas positivas en torno a la figura de Rodrigo Ávila: "Ex presidentes apoyaron ayer a Rodrigo Ávila" (EDH, p.30, marzo 
13), "Ávila ayudó a aclarar asesinato de diputados" (EDH, p. 3, marzo 06), "Ávila con ex presidentes y empresarios a recta final" (LPG, p. 8, marzo 13), "Ávila entrega vivienda con energía solar" (LPG, p. 12, marzo 07). Este tipo de notas parecía reforzar la idea de que Ávila iba bien encaminado a continuar representando la figura del líder de ARENA. Este fenómeno se vio reforzado en la prensa escrita por el hecho de que las notas informativas que se referían a Mauricio Funes y al FMLN en general eran de corte negativo: "Empresarios piden a Funes no generalizar acusaciones" (LPG, p. 8, marzo 07), "Jefe de prensa de Funes agrede a periodistas" (LPG, p. 13, marzo 11), "Congresistas de EE.UU. repudian actitud de Funes" (EDH, p.4, marzo 10), "Funes: 'Cancelación del TPS no me afecta a mí" (EDH, p.10, marzo 13).

Por su parte, la publicidad de ARENA fue mutando el personaje del líder mesiánico en facetas diversas con reciclajes visuales y prestamos simbólicos de campañas anteriores. El buen desarrollo del líder caudillista o la figura presidencialista afirmada en la propaganda electoral de otros años no alcanzó los niveles esperados de identificación con el público salvadoreño. La imagen publicitaria no siempre es más fuerte que la identidad institucional.

\section{Cuadro $\mathrm{N}^{\circ} 1$}

Evolución iconográfica del líder en la publicidad política de ARENA, 2009

\begin{tabular}{|l|l|l|}
\hline Campaña & Imagen & Sentido \\
\hline $\begin{array}{l}\text { Rodrigo Ávila, } \\
\text { un hombre } \\
\text { Con valores }\end{array}$ & $\begin{array}{l}\text { Patriarca: cabeza de familia } \\
\text { Administrador: responsabilidad y y } \\
\text { experiencia. }\end{array}$ & $\begin{array}{l}\text { Lo moral, la rectitud, las buenas } \\
\text { Costumbres como principales atri- } \\
\text { butos que definen su liderazgo. }\end{array}$ \\
\hline $\begin{array}{l}\text { Rodrigo Ávila } \\
\text { presidente } \\
\text { Una nueva era } \\
\text { para El Salvador }\end{array}$ & $\begin{array}{l}\text { Ciudadano, no-político: responsa- } \\
\text { ble y decidido a tomar las riendas } \\
\text { por un nuevo El Salvador. } \\
\text { El vigilante imparcial: centinela } \\
\text { determinado a combatir la corrup- } \\
\text { ción en todos sus niveles. }\end{array}$ & $\begin{array}{l}\text { Alude a la figura del ciudadano co- } \\
\text { tidiano, cuestiona los políticos y las } \\
\text { promesas de campaña. } \\
\text { Resuelve finalmente con su imagen } \\
\text { de administrador de seguridad pú- } \\
\text { blica en la dirección de la PNC. }\end{array}$ \\
\hline $\begin{array}{l}\text { Rodrigo Ávila } \\
\text { presidente } \\
\text { Firma de } \\
\text { compromisos }\end{array}$ & $\begin{array}{l}\text { Administrador consciente: hones- } \\
\text { tidad y responsabilidad como atri- } \\
\text { butos de liderazgo } \\
\text { Recto y probo: integridad y honesti- } \\
\text { dad como atributos administrativos. }\end{array}$ & $\begin{array}{l}\text { La firma frente a diferentes co- } \\
\text { lectivos pretende ser el reflejo } \\
\text { de un lider respetado, escucha- } \\
\text { do y creíble. } \\
\text { Un líder seguido por todos, mu- } \\
\text { jeres, obreros, niños, salvadore- } \\
\text { nos en general. }\end{array}$ \\
\hline
\end{tabular}




\begin{tabular}{|c|c|c|}
\hline $\begin{array}{l}\text { Rodrigo Ávila } \\
\text { presidente del } \\
\text { empleo } \\
\text { Confianza, más } \\
\text { empleos }\end{array}$ & $\begin{array}{l}\text { El cabeza de grupo: Rodrigo se } \\
\text { manifiesta como el director del } \\
\text { COENA. } \\
\text { El líder inclusivo: el equipo de al- } \\
\text { caldes, diputados se integra por re- } \\
\text { presentantes de grupos emergentes }\end{array}$ & $\begin{array}{l}\text { Los diversos colectivos se ven } \\
\text { representados en el grupo de } \\
\text { diputados por ARENA y todos } \\
\text { ellos reflejan la sólida morali- } \\
\text { dad del candidato a la presiden- } \\
\text { cia generando confianza como } \\
\text { modo de propiciar empleos en } \\
\text { El Salvador. }\end{array}$ \\
\hline
\end{tabular}

Los diversos préstamos icónicos observados en la campaña de Rodrigo Ávila generaron una ambigüedad en la consolidación de su imagen como líder; cada uno fue ensayando facetas diversas, pero no se alcanzaron los niveles esperados de popularidad. Ante tal insuficiencia, la estrategia de campaña de
ARENA cobró un giro distinto, sustituyendo el protagonismo del candidato por la presencia institucional del partido. La lógica caudillista mantenida en las campañas anteriores se desmorona y ARENA debe recurrir a una estrategia de descrédito con narrativas de una mitología apocalíptica.

\section{El mito del progreso y la defensa del sistema de libertades}

E I discurso de ARENA sobre el progreso y la libertad sostiene que las principales fuerzas que permanentemente están promocionando los avances del país son el partido oficial, el mercado y la elite empresarial. Este discurso entra en desacuerdo con cualquier tipo de comentario que pudiera cuestionar sus políticas económicas o sociales. Desde una perspectiva mítica, el partido asocia esas políticas económicas con el bien común; la elite empresarial se convierte en la fuerza que dinamiza el mercado de trabajo, y el pueblo en la colectividad que recibe los beneficios que las dinámicas económicas generan. Al mismo tiempo, el FMLN se percibe desde el mito del progreso como la fuerza ne- gativa que puede destruir los avances alcanzados. La temática de dicho progreso y la de los peligros que lo acechan se abordó principalmente desde las entrevistas que realizaron los matutinos con ex presidentes de ARENA y con empresarios. Cuando La Prensa Gráfica le preguntó al presidente Saca qué le hacía pensar que los indecisos se inclinarían a votar por Rodrigo Ávila, el mandatario respondió: "Históricamente ha sido gente que es conservadora, desean conservar su trabajo, sus viviendas, su familia, son gente cristiana, gente que no quiere experimentos socialistas del siglo XXI y todos esos inventos suramericanos que son refritos de un sistema que no ha funcionado" (p. 6, 5 de marzo). 
En este entramado discursivo la idea de "pueblo" es una figura simbólica preponderante dentro de la mitología del discurso arenero. Bajo esta perspectiva política, el pueblo nunca es un pueblo que vive en total estado de bienestar. La línea discursiva de ARENA no destaca tanto el mantenimiento de una sostenibilidad que ya alcanzó una meta, sino más bien afirmaciones relacionadas con la búsqueda de más oportunidades laborales y económicas. Si se mira de cerca, las campañas areneras son paradójicas, porque están indicando que el pueblo tiene muchas necesidades y carencias a pesar de que el partido ya tiene casi veinte años en el poder, pero al mismo tiempo están sugiriendo que esta situación de precariedad es resultado del desgaste de la guerra o de problemas externos que afectan al país, como la crisis económica, por ejemplo, y que lo único que el partido está tratando de hacer es remediar esta situación poco a poco, pero que no se puede abarcar todo. Esta lectura de un pueblo victimiza- do por la izquierda, castigado a través de los fenómenos naturales por la ira de la Madre Tierra y afectado por las crisis mundiales siempre va a necesitar de un líder que lo guíe, como se observó anteriormente.

Por otra parte, la insistencia en la paciencia del electorado fue un fenómeno particularmente notorio durante las elecciones presidenciales de 2009. Sin embargo, esta tendencia comenzó con la campaña presidencial del 2003, a través de la figura de Antonio Saca y su permanente discurso del "sistema de libertades". Dentro de esa noción de "sistema de libertades" la figura de "pueblo" (representada por los votantes) es muy importante, pues son los votantes precisamente quienes eligen a los gobiernos. En el siguiente cuadro se muestran algunas afirmaciones de entrevistados que hacen énfasis en el discurso sobre el mito del progreso y la defensa de las libertades, y cómo los principales matutinos se centraron en este tipo de tópicos y enfoques.

\section{Cuadro $\mathrm{N}^{\circ} 2$}

La reproducción del discurso del mito del progreso y de la defensa del sistema de libertades en el contenido de las entrevistas

\begin{tabular}{|c|c|}
\hline Titular / Entrevistado & Reproducción del discurso mítico \\
\hline $\begin{array}{l}\text { "Me preocupa que el FMLN } \\
\text { hable de socialismo" } \\
\text { Francisco Calleja } \\
\text { (Empresario) }\end{array}$ & $\begin{array}{l}\text { - "Asegura que el principal reto de los empresarios salvadoreños para } \\
\text { afrontar la actual crisis mundial es continuar su rol de producir, con- } \\
\text { tinuar generando empleos e inversión." } \\
\text { - "¿Cree que el llamado socialismo del siglo XXI permita la genera- } \\
\text { ción de empleos y el fortalecimiento de la libre empresa? } \\
\text { Definitivamente no lo permite, el socialismo del siglo XXI incrementa } \\
\text { el desempleo y al mismo tiempo debilita el sistema de la libre empre- } \\
\text { sa, además de anular la inversión nacional y extranjera, y eso obliga } \\
\text { al cierre de puestos de trabajo." (LPG, pp. } 2-3,6 \text { de marzo) }\end{array}$ \\
\hline
\end{tabular}




\begin{tabular}{|c|c|}
\hline $\begin{array}{l}\text { "Con el FMLN albergamos } \\
\text { una gran cantidad de dudas, } \\
\text { reservas e incluso temores" } \\
\text { Federico Colorado } \\
\text { (Presidente ANEP) }\end{array}$ & $\begin{array}{l}\text { "Todos estos temores de lo que está ocurriendo en otros países } \\
\text { de Latinoamérica no son infundados. Tenemos las posiciones } \\
\text { de empresarios de estos países, dondo expresan claramente la } \\
\text { forma en la que se están implementando programas de gobier- } \\
\text { no que son contrarios al desarrollo de un sistema de libertades, } \\
\text { de libre empresa" (LPG, p. } 11,11 \text { de marzo) }\end{array}$ \\
\hline $\begin{array}{l}\text { "Hay una abierta } \\
\text { Confrontación entre el FMLN y } \\
\text { el sector privado" } \\
\text { Rafael Barraza } \\
\text { (Director General ESEN) }\end{array}$ & $\begin{array}{l}\text { "En la medida que se genere confianza en el sector privado y } \\
\text { en el futuro del país, se van a tener mejores resultados. La ver- } \\
\text { dad es que analizanclo eso uno realmente duda que el FMLN } \\
\text { va a poder lograr confianza en el sector privado para poder } \\
\text { gobernar, si ganara las elecciones, y uno pensaría que ARENA, } \\
\text { habiendo estado en el poder } 20 \text { años, obviamente va a hacer } \\
\text { un trabajo mucho más tranquilo y mucho más fácil el imple- } \\
\text { mentar un plan de gobierno orientado a resolver los problemas } \\
\text { de esta situación internacional" (LPG, p. 5, } 12 \text { de marzo) }\end{array}$ \\
\hline $\begin{array}{l}\text { "Saca pide voto por la libertad } \\
\text { y la democracia" } \\
\text { Antonio Saca } \\
\text { (Presidente de El Salvador) }\end{array}$ & $\begin{array}{l}\text { - "¿Qué se juega el país en la elección del } 15 \text { de marzo? } \\
\text { Nos jugamos un sistema de vida democrático. Nos jugamos el } \\
\text { sistema de libertadles, las cuales generalmente no extrañamos } \\
\text { porque no las hemos perdido (...) Y no me estoy refiriendo a } \\
\text { modelos económicos, estoy hablando del sistema de libertades } \\
\text { que nos permite tener libertad de culto, de expresión, de orga- } \\
\text { nización y de poder decir lo que uno quiera." } \\
\text { - "¿Cree que el FMLN no ha cambiado y sigue pensando es des- } \\
\text { truir el sistema de libertades? } \\
\text { Es que el FMLN es un partido antisistema y, por lo tanto, si es } \\
\text { antisistema, sus estatutos, los pensamientos de sus dirigentes, es- } \\
\text { tán enfocados hacia eso. No creo que el Espíritu Santo les haya } \\
\text { iluminado la cabeza y de repente se convirtieron en cristianos y } \\
\text { en gente que cree en la democracia" (EDH, pp. } 2-3,5 \text { de marzo) }\end{array}$ \\
\hline $\begin{array}{l}\text { "El país se juega el sistema de } \\
\text { libertades" } \\
\text { Armando Calderón Sol (ex } \\
\text { presidente de El Salvador) }\end{array}$ & $\begin{array}{l}\text { "¿Qué se juega el país el } 15 \text { de marzo? } \\
\text { El } 15 \text { de marzo será un día histórico porque el país se está jugando } \\
\text { la estabilidad, el proceso democrático, lo que hemos venido cons- } \\
\text { truyendo en estos años clespués de la guerra fraticida que tuvimos. El } \\
\text { Salvador, el } 15 \text { de marzo, tiene un enorme reto, que es el votar por } \\
\text { la estabilidad, por la democracia, por la familia, por los valores... o } \\
\text { votar por la incertidumbre, por la ineficacia, por los contestatarios, } \\
\text { por la anarquía, por la barbarie." (EDH, p. } 6,7 \text { de marzo) }\end{array}$ \\
\hline $\begin{array}{l}\text { "Ante la crisis no estamo } \\
\text { experimentos" } \\
\text { Roberto Murray Meza } \\
\text { (empresario) }\end{array}$ & $\begin{array}{l}\text { "¿Qué está en juego el domingo } 15 \text { de marzo? } \\
\text { Durante los últimos } 20 \text { años, los salvadoreños hemos trabajado con } \\
\text { mucho esfuerzo para crear un nuevo país, y aunque todavía tenemos } \\
\text { muchos retos por delante, hemos recorrido un gran camino en el } \\
\text { desarrollo económico y social. Se han creado instituciones que nos } \\
\text { permiten vivir en democracia con un sistema de libertades personales } \\
\text { y jurídicas. Se ha invertido mucho para mejorar el nivel de vida de } \\
\text { nuestra gente y se ha invertido en un sistema que promueve la liber- } \\
\text { tad de mercado, regulando los mercados (...) No podemos arriesgar } \\
\text { lo que tanto nos ha costado." (EDH, p. } 2,14 \text { de marzo) }\end{array}$ \\
\hline
\end{tabular}

El discurso de ARENA siempre ha destacado cuáles son las libertades que se pueden perder si el electorado opta de forma "ingenua" por el FMLN. La sola posibilidad de concebir el FMLN como opción 
política es vista como algo similar a la transgresión de un escudo que, según los miembros de ARENA, ellos han creado para proteger la "libertad". De acuerdo con los tópicos en los que se centraron los principales medios de la prensa escrita y a partir de las declaraciones de los entrevistados, la gente podría perder la libertad de culto, la libertad de poseer propiedad privada, la libertad de escalar socialmente, la libertad de emplearse en la empresa privada, la libertad de vivir en democracia, la libertad de elegir a los gobernantes y la libertad de expresión, entre otras "libertades" más. El cuadro anterior muestra cómo personalidades del ámbito político, empresarial y educativo reproducen ese discurso y como los principales matutinos colocaron de manera frecuente en su agenda estos tópicos durante los últimos días antes de la elección presidencial.

Al hablar de las bondades de ARENA, de los temores de los empresarios, de las libertades que están en juego, y de 20 años de experiencia y de logros, se refuerza la idea de la bestia del mal (el FMLN, el socialismo o la influencia de Hugo Chávez) como amenaza permanente del sistema de libertades. Dentro del discurso electoral arenero, cuando la bestia reine (cuando la gente se equivoque y le permita al FMLN tener acceso al Ejecutivo) causará inestabilidad, caos, desesperanza y retroceso (la pérdida del sistema de libertades). Aquellos que se rindan ante las ventajas ilusorias del mal serán traicionados tarde o temprano por la bestia y serán condenados. El reinado de la bestia tiene en el pensamiento cristiano un principio y un fin que sirve para determinar quiénes son los que verdaderamente han creído y se han mantenido a la espera. Ellos serán premiados. En el caso de ARENA, la gestión de su líder presidencial arenero, como la del Mesías, tiende hacia un futuro esperanzador para salvaguardar el sistema de libertades y la línea de progreso, mecanismos que permanentemente se encuentran amenazados por un "monstruo". De acuerdo al discurso arenero, en la gestión del partido oficial hay una proyección de vida esperanzadora: El Salvador siempre avanza y se está trabajando para mejorar, para apostar por un sistema de vida al que deben aspirar los ciudadanos sensatos.

La gestión de ARENA se presentó publicitariamente como un gobierno de logros tangibles: el mejoramiento del sistema de vida de los salvadoreños se hizo visible con calles de tránsito fluido, ordenado, centros comerciales y rostros sonrientes, al mismo tiempo que se aludió a la necesidad del continuismo de gobierno para potenciar otros proyectos no concluidos o alcanzados durante la gestión del presidente Saca. La utopía realizable adquirió niveles icónicos familiares en la publicidad de ARENA, apoyada además por la línea dominante de la publicidad gubernamental. Así, la publicidad gubernamental fue enumerando la eficacia de pro- 
yectos como FOSALUD y el acceso gratis al estudio de bachillerato, entre otros. Se emplearon perífrasis verbales para indicar una acción en tiempo presente durativo, lo que a su vez creó la sonoridad recurrente de una promesa prolongada, más no una resolución o finalización concreta de metas. Contrario a ello, a la vez la publicidad del partido in- dicó los problemas no superados en El Salvador. Este señalamiento configuró un mensaje ambiguo cuando el mismo partido de gobierno es el que se vio cuestionado por su candidato cuando hacía referencia a temas como la seguridad pública, la impunidad, el alto costo de las medicinas y la extrema pobreza.

\section{Algunas conclusiones}

os dogmas relacionados con la idea de "civilización", de progreso y de desarrollo permanente son todos elementos que conforman el campo semántico de la forma cómo vivimos y sufrimos los mitos hoy, en la existencia del día a día. En el caso específico de la narrativa mítica de ARENA, la idea de la espera, del continuo avance, fue una figura preponderante de la campaña presidencial de 2009. Este discurso supone que si no se ha dado el Apocalipsis es porque la esperanza del pueblo ha sostenido la situación y ha permitido que se siga en la espera. Esta figura mítica se adecua al discurso político para indicar que cada líder es importante, pero que no se ha alcanzado un bienestar final porque cada uno de ellos es solo una figura competente (un elegido) y que hace falta seguir esperando por otros líderes del partido que continúen la jornada (otros mensajeros del bien). Hay que observar entonces cómo se configura la idea de "pueblo" en el discurso de ARENA, un pueblo paciente que debe esperar, confiar y proteger sus libertades a través del voto.

Por otra parte, desde la perspectiva de los medios, de la propaganda partidaria y del discurso oficial se ejerce una racionalidad formal que condiciona a no dejarse cuestionar por la realidad. Más bien se promueve la desinformación: un tratamiento superficial de los temas, sucesos, informes y propagandas. Dentro de esta perspectiva y desde este tipo de discursos, en realidad la valoración antropológica del ser humano pasa a un segundo plano, y son el mercado y la propiedad los que ostentan posiciones más privilegiadas. El pensamiento mítico es lo que rige ese sistema de realidad, ese sistema de mundo y de dogmas.

El horizonte de la realidad se convierte ahora en el nuevo mito de la modernidad: la vida productiva, la vida de progreso y desarrollo está en constante movimiento pues nunca llegamos a un desarrollo total, pero tenemos ese desarrollo como 
el camino que debemos seguir en pos de una promesa. Un camino lleno de espinas y de obstáculos (el precio que hay que pagar por el desarrollo), pero que vale la pena recorrer porque en algún punto nos está esperando una recompensa. Las historias, es decir, las diferentes versiones de realidad se confunden con la historia a partir de narrativas fáciles de incorporar a la vida cotidiana por ser discursos que se repiten constantemente, discursos con los que la gente a través de la costumbre, la fe, la esperanza o el miedo espera establecer determinadas certezas y dejar atrás la incertidumbre.

En el caso del discurso mítico del partido ARENA, como muchas otras narrativas del mundo de la política, de la cultura, de la literatura, del cine y de la religión se retoman

\section{Bibliografía}

Páginas Web

Address to a Joint Session of Congress and the American People

http://www.whitehouse.gov/news/releases/2001/09/20010920-8.html

Discurso en el que Bush acuñó el término, "El Eje del Mal" (The State of the Union Address, en enero 29 de 2002)

http://en.wikipedia.org/wiki/The_ axis_of_evil

Textos

Hinkelammert, Franz. Hacia una crítica de la razón mítica: el contenidos presentes en diferentes textos, es decir, temáticas que son de fácil asimilación y que tienden a buscar una promesa, una recompensa más allá del arco iris, una esperanza que ayude a comprender la necesidad de la sacrificialidad. Los textos y los discursos no son solo narrativas que se pueden percibir desde un punto de vista literal y formal. Las figuras literarias y muchas de las declaraciones que hacen alusión referentes religiosos van más allá de lo metafórico, y proporcionan instrumentos para analizar la realidad de hoy sin creer ilusoriamente que ya rompimos con el pasado. Estos textos son valiosos en la medida que proporcionan pistas interpretativas, ayudan a entender cómo están configuradas las narrativas dominantes, y cuál podría ser el sentido de la historia.

laberinto de la modernidad. Materiales para la discusión. Editorial Arlekín; San José, Costa Rica, 2007.

Texto de El Apocalipsis

Revistas

- Revistas ECA, Estudios Centroamericanos. UCA Editores. EI Salvador.

Números:

672, Octubre 2004

- Editorial: Criterios para juzgar un mito de derecha

675/676, Enero-Febrero 2005 
- González, J.; Guzmán, N.; Peraza, X.; Rivera, C. La importancia de los dueños de la historia. Estudio narratológico sobre la complicidad de los medios en la recreación del pasado.

Periódicos

La Prensa Gráfica y El Diario de Hoy. Ediciones del 6 al 14 de marzo de 2009

\section{Notas}

1 Hinkelammert, F. Hacia una critica de la razón mítica. El laberinto de la modernidad. Capítulo III, p. 163.
Propaganda

Anuncios publicitarios de la campaña presidencial 2009

Tesis

Aurora, A. J., "La construcción del discurso político electoral de ARENA: elecciones 2006". Tesis presentada al Programa Centroamericano de Postgrado para optar al grado de Doctora en Ciencias Sociales de FLACSO. 